\title{
Plasma renin levels are associated with cardiac function in primary adrenal insufficiency
}

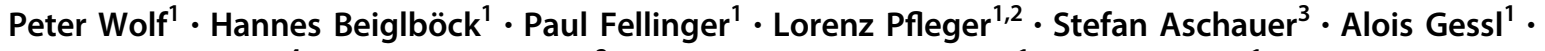 \\ Rodrig Marculescu ${ }^{4}$ - Siegfried Trattnig ${ }^{2}$ - Alexandra Kautzky-Willer ${ }^{1}$ - Anton Luger ${ }^{1} \cdot$ Yvonne Winhofer $^{1}$. \\ Martin Krššák ${ }^{1,2} \cdot$ Michael Krebs $^{1}$
}

Received: 18 February 2019 / Accepted: 28 May 2019 / Published online: 8 June 2019

(c) The Author(s) 2019

\begin{abstract}
Background Despite adequate glucocorticoid (GC) and mineralocorticoid (MC) replacement therapy, primary adrenal insufficiency (AI) is associated with an increased mortality, mainly due to cardiovascular disease. The role of MC replacement is not known. Therefore, we assessed whether renin concentrations during routine GC and MC substitution therapy are associated with heart function and morphology.

Methods Thirty two patients with primary AI were included in a cross-sectional case-control study. In total, 17 patients and 34 healthy controls (age: $48 \pm 12$ vs. $46 \pm 18$ years; BMI: $23 \pm 3$ vs. $24 \pm 3 \mathrm{~kg} / \mathrm{m}^{2}$ ) underwent magnetic resonance spectroscopy and imaging measurements to assess cardiac function, morphology, ectopic lipids, and visceral/subcutaneous fat mass. Patients were divided according to their actual plasma renin concentration at the study visit (Actual-Renin ${ }_{\text {low }}$ vs. Actual-Renin $_{\text {high }}$ ) and their median plasma renin concentration of previous visits (Median-Renin $n_{\text {low }}$ vs. Median-Renin $n_{\text {high }}$ ). Results Ejection fraction was higher $(67 \pm 5$ vs. $55 \pm 3 \% ; p=0.001)$ and left ventricular mass was lower $(60 \pm 9$ vs. $73 \pm$ $\left.10 \mathrm{~g} / \mathrm{m}^{2} ; p=0.025\right)$ in Actual-Renin high. $_{\text {Median-Renin }}$ high was associated with lower cardiac mass $\left(64 \pm 9 \mathrm{vs} .76 \pm 11 \mathrm{~g} / \mathrm{m}^{2}\right.$; $p=0.029$ ). Blood pressure, glucose, and lipid metabolism, as well as ectopic lipid content, pericardial fat mass, and visceral/ subcutaneous fat were not different between the groups. Compared with controls, ejection fraction was significantly lower in patients with AI (56 \pm 4 vs. $63 \pm 8 \% ; p=0.019$ ). No differences were found in patients with $\leq 20 \mathrm{mg}$ compared with $>20 \mathrm{mg}$ of hydrocortisone per day.

Conclusions Higher renin concentrations are associated with more favorable cardiac function and morphology in patients with primary AI.
\end{abstract}

Keywords Ectopic lipids $\cdot$ Addison's disease $\cdot$ Glucocorticoid replacement therapy $\cdot$ Renin-angiotensin-aldosterone system

Michael Krebs

michael.krebs@meduniwien.ac.at

1 Division of Endocrinology and Metabolism, Department of Internal Medicine III, Medical University of Vienna, Vienna, Austria

2 Centre of Excellence - High Field MR, Department of Biomedical Imaging and Image-guided Therapy, Medical University of Vienna, Vienna, Austria

3 Division of Cardiology, Department of Internal Medicine II, Medical University of Vienna, Vienna, Austria

4 Department of Laboratory Medicine, Medical University of Vienna, Vienna, Austria

\section{Background}

Primary adrenal insufficiency (AI) is characterized by potentially life-threatening glucocorticoid (GC) and mineralocorticoid (MC) deficiency, requiring lifelong hormone replacement therapy [1]. In contrast to reports of retrospective cohort studies indicating that regular GC and MC substitution therapy might normalize life expectancy, with excess mortality only in patients diagnosed at a younger age [2], other evidence hints at a more than twofold increase in mortality in affected patients compared with the general population, mainly due to increased risk of cardiovascular disease [3, 4].

There are several explanations addressing cardiovascular risk factors, which mainly focus on GC replacement therapy. For example, even a small oversupply of daily GC 
dose is associated with an adverse cardiovascular risk profile, including an increase in waist circumference, blood pressure, and fasting glucose [5]. Also, the timing of GC replacement therapy might be of importance. In contrast to conventional therapy, when GC is administered two to three times daily to mimic the physiological cortisol rhythm, studies investigating modified-release preparations of hydrocortisone report significant improvements in body mass index (BMI), glucose, and lipid metabolism [6, 7].

Only little is known about the role of MC replacement therapy in the development of cardiovascular diseases in patients suffering from primary AI. The most important hormone in MC metabolism is aldosterone, which is mainly regulated by the renin-angiotensin-aldosterone (RAS) system. Excessive aldosterone secretion is well known to be associated with an increased mortality, due to myocardial infarction, stroke, or heart failure $[8,9]$. On the other hand, RAS consists of an enzymatic cascade of various angiotensin metabolites, which also exert effects on cardiovascular risk factors. The most prominent RAS metabolite is angiotensin 2 (AT2), which promotes vasoconstriction, cardiac remodeling, and modulates systemic inflammatory response to vascular injury similar to aldosterone $[10,11]$. In contrast, other angiotensin metabolites like Angiotensin 1-7 (Ang1-7) are potentially cardioprotective and might counterbalance the adverse effects of AT2 [12]. Preliminary data of our study group indicate that the RAS is highly upregulated with increased concentrations of AT2 and Ang1-7 in patients suffering from primary AI, despite adequate GC and MC replacement therapy [13]. In addition, plasma renin concentration strongly correlates with RAS activity and AT2 [13].

Clinical practice guidelines recommend titration of MC replacement therapy to aim a plasma renin concentration in the upper reference range [14]. However, clinical evidence supporting this recommendation is scarce and the role of $\mathrm{MC}$ in the development of cardiovascular disease in patients with primary AI is unknown. Concentrations of both aldosterone and AT2 are closely correlated with plasma renin levels. Therefore, we aimed to investigate the impact of plasma renin concentration on cardiovascular risk factors in patients with stable hormone replacement therapy.

\section{Methods}

We performed a cross-sectional, single-center, pilot study at the Medical University of Vienna, Department of Internal Medicine III, Division of Endocrinology and Metabolism. The study protocol was approved by the local ethics committee and written informed consent was obtained from all participating subjects. This study was conducted in conformance with the relevant guidelines and regulations, i.e., principles of the Declaration of Helsinki and the ICH-GCP guidelines.

Patients with confirmed primary AI treated at the endocrine outpatients' clinic at the Medical University of Vienna were searched for available plasma renin concentrations of previous visits. Included patients had to be on stable GC and $\mathrm{MC}$ replacement therapy for at least 6 months prior to the study visit. Exclusion criteria were concomitant antihypertensive therapy with ACE inhibitors/AT2 antagonists, diabetes mellitus (type 1 and 2), elevated liver enzymes $>$ $3 \times$ upper limit of normal, medical history of cardiovascular disease, and advanced chronic kidney disease (estimated glomerular filtration rate $<45 \mathrm{ml} / \mathrm{min}$ ). In total, 32 patients with primary adrenal insufficiency could be included (see Fig. 1). In all patients, primary AI was confirmed at initial diagnosis by morning cortisol $<5 \mu \mathrm{g} / \mathrm{dl}$, together with $\mathrm{ACTH}>2$-fold the upper limit of normal, according to current guidelines [14]. The cause of primary AI was autoimmune adrenalitis in most of the patients, confirmed by positive testing of 21-hydroxylase antibodies. Two patients suffered from adrenoleukodystrophy. In all patients, GC replacement therapy was performed with standard rapid-release hydrocortisone. Twenty nine patients received daily $\mathrm{MC}$ replacement therapy.

All patients underwent clinical examination and blood tests, as well as the assessment of anthropometric characteristics, a Schellong test, and a transthoracic echocardiography.

Seventeen patients volunteered to participate at magnetic resonance (MR) spectroscopy and imaging measurements at a second study day. These patients were compared with 34 healthy control subjects matched for age and body mass index (BMI) in a 1:2 ratio.

In order to compare RAS activity, patients were divided into two groups of similar sample size, according to their actual plasma renin concentration (Actual-Renin ${ }_{\text {low }}$ : $<50 \mu \mathrm{IU} / \mathrm{ml}$ and Actual-Renin high $:>50 \mu \mathrm{IU} / \mathrm{ml})$, as well as to their median plasma renin concentration of previous visits at the endocrine outpatients' clinic (Median-Renin ${ }_{\text {low }}$ : $<100 \mu \mathrm{IU} / \mathrm{ml}$ and Median-Renin high $\left._{1}:>100 \mu \mathrm{IU} / \mathrm{ml}\right)$. The normal range in supine position of the renin assay used was 4.4-46.1 $\mu \mathrm{IU} / \mathrm{ml}$ with a CV of $6.6 \%$. Actual-Renin ${ }_{\text {high }}$ reflects about >onefold upper-normal range and MedianRenin $_{\text {high }}$ about $>$ twofold upper-normal range. Different cutoff values for actual-Renin and Median-Renin had to be chosen to obtain two groups of comparable sample size. The mean time between the first and last of these previous visits was $31 \pm 16$ months.

In total, $87.5 \%$ of all included patients stayed within their groups, i.e., Actual-Renin ${ }_{\text {low }}=$ Median-Renin $_{\text {low }} /$ ActualRenin $_{\text {high }}=$ Median-Renin $n_{\text {high }}$. Two patients in the ActualRenin $_{\text {low }}$ group switched to the Median-Renin $n_{\text {high }}$ group and vice versa. 
Fig. 1 Flowchart: recruitment process of all patients with available plasma renin concentrations of previous visits at the endocrine outpatients' clinic. TTE transthoracic echocardiography, VAT visceral adipose tissue, SAT

subcutaneous adipose tissue

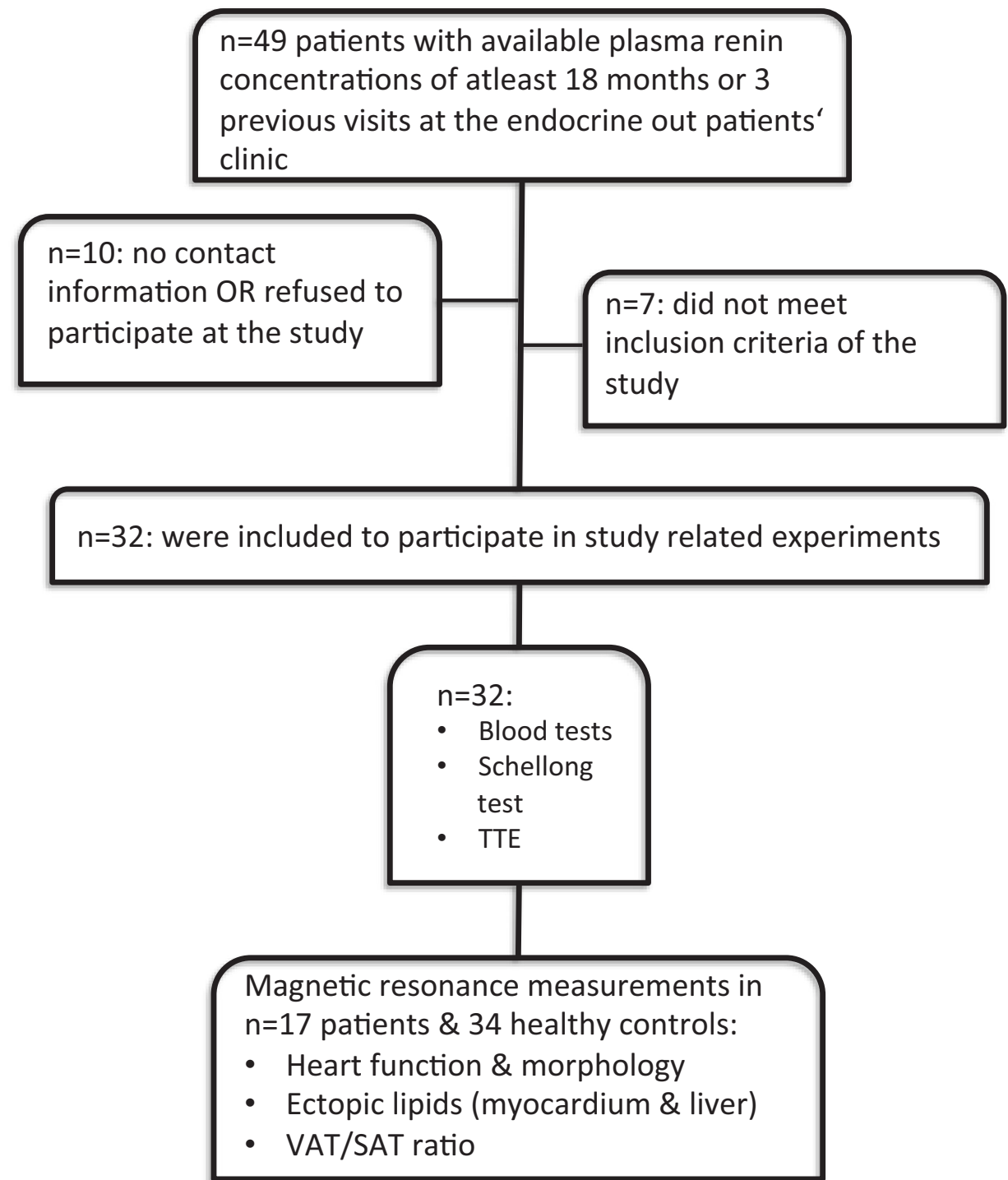

To evaluate the impact of daily glucocorticoid replacement therapy, patients were divided into daily hydrocortisone dose of $\leq 20 \mathrm{mg} /$ day and daily hydrocortisone dose of $>20 \mathrm{mg} /$ day.

Blood tests were performed under standardized conditions in a seated position, following at least $15 \mathrm{~min}$ of physical rest. Laboratory parameters were measured by routine lab methods at the department of laboratory medicine of the Medical University of Vienna (http://www. kimcl.at).

All transthoracic echocardiography (TTE) measurements were performed using commercially available equipment (Vivid 7 aGE Healthcare, Chicago, IL) by the same experienced physician according to current guidelines [15].

To evaluate postural hypotension, Schellong test was performed in all patients. Therefore, blood pressure was measured every $2 \mathrm{~min}$ for $10 \mathrm{~min}$ in supine position and immediately, as well as every $2 \mathrm{~min}$ for $10 \mathrm{~min}$ after promptly getting up.

All magnetic resonance spectroscopy and imaging measurements were performed on a 3.0-T Tim Trio System (Siemens Healthcare, Erlangen, Germany) operated with a Syngo VB17 (Siemens Healthcare) user interface after an overnight fast. Myocardial lipid content (MYCL) was measured by ECG-gated single-voxel-localized ${ }^{1} \mathrm{H}-\mathrm{MRS}$. The volume of interest was positioned in the interventricular septum to avoid signal alterations by the epicardial fat. PRESS sequence (typical VOI $=15 \times 10 \times 30 \mathrm{~mm}^{3}$; TE $=$ $30 \mathrm{~ms} ; \mathrm{NA}=2 \times 4$ for water signal; $2 \times 8$ for watersuppressed signal) data acquisition was performed during multiple single-breath holds. MYCL was calculated from the ratio of the summed area of methylene and methyl groups to that of water, following the individual spin-spin relaxation correction as the percentage of tissue water MRS 
signal. For cardiac MR visualization and analyses, ARGUS software (Siemens AG Healthcare, Erlangen, Germany) was used. Left ventricular function by MR imaging was assessed manually and has also been described in detail previously [16-18]. As published in ref. [18], pericardial fat (PERI), i.e., paracardial + epicardial adipose tissue, regions of interest were manually drawn along the borders of the fat surrounding the heart in three slices from the apex to the pulmonary trunk. The mean is given in $\mathrm{cm}^{2}$. Quantitation of hepatocellular lipid content (HCL) was performed using localized single-voxel ${ }^{1} \mathrm{H}$-MRS like that published previously [16-18]. PRESS sequence (VOI $=3 \times 3 \times 3 \mathrm{~cm}^{3}$; $\mathrm{TE}=30 \mathrm{~ms} ; \mathrm{NA}=4$ for each $\mathrm{TE}$ ) data acquisition was performed during single-breath hold. HCL was calculated from the ratio of the summed area of methylene and methyl lipid signals to that of water following the individual spin-spin relaxation correction as the percentage of tissue total MRS signal. The amount of visceral and subcutaneous adipose tissue (VAT, $\mathrm{SAT}$ ) was assessed from $\mathrm{T}_{1}$-weighted axial 2D turbo spin-echo multislice images $(\mathrm{TE}=40 \mathrm{~ms}$, $\mathrm{TR}=450 \mathrm{~ms}$, Matrix $256 \times 144$, and FOV adjusted to the body size) over the abdominal region within single-breath hold. The signal of adipose tissue within the image slice in the height of L4-L5 was semiautomatically segmented offline within Jim 5.0 Image Analysis software (Xinapse Systems Ltd, West Bergholt, UK) and the amount of VAT and SAT was given as area within the slice in $\mathrm{cm}^{2}$ [16].

Based on our recent data in nondiabetic individuals [16], a sample size of eight patients per group was sufficient to observe a significant difference in the primary outcome parameter left ventricular myocardial mass with alpha $=$ 0.05 and beta $=0.2$ between the groups.

Exploratory statistical analysis was performed using SPSS Version 24 (IBM, Armonk, NY, USA). Normal distribution was checked by data visualization. Data are given as means \pm standard deviation or as median (minimum; maximum). Comparison between groups was performed by unpaired Student's $t$ tests or Mann-Whitney $U$ tests. Nominal parameters were compared by chi-square tests. Analysis of variances was calculated with ANOVA. Correlation analysis was calculated with Spearman's correlation coefficient (r). Due to the hypothesis-generating design of the study, data were not corrected for multiple testing. The level of statistical significance was set at $\alpha<0.05$.

\section{Results}

Thirty two patients (women/men: 21/11; age: $55 \pm 17$ years; BMI: $25 \pm 5 \mathrm{~kg} / \mathrm{m}^{2}$; disease duration: $19 \pm 10$ years) were included in this study. All patients were on stable GC replacement therapy (mean GC dose: $23 \pm 5 \mathrm{mg}$ of hydrocortone/day) and 30 patients were on stable $\mathrm{MC}$ replacement therapy (mean MC dose: $0.06 \pm 0.03 \mathrm{mg}$ of fludrocortisone/day). In nine patients, daily GC dose exceeded $20 \mathrm{mg}$ of hydrocortisone per day.

TTE showed normal left ventricular (ejection fraction: $57 \pm 5 \%$; average global longitudinal strain: $-19 \pm 2 \%$ ) and right ventricular (TAPSE: $26 \pm 4 \mathrm{~mm}$ ) systolic function in all investigated patients. Grade I diastolic dysfunction, i.e., impaired diastolic relaxation, was present in 13 patients $(43 \%)$. One patient (3\%) presented with grade III diastolic dysfunction.

\section{The impact of actual plasma renin concentration}

Patients suffering from primary AI were grouped according to their actual plasma renin concentration measured at the study visit (Actual-Renin ${ }_{\text {low }}$ vs. Actual-Renin $n_{\text {high }}$ ). Anthropometric characteristics, disease duration, as well as daily dose of GC and MC replacement therapy were comparable (see Table 1).

With regard to glucose metabolism, HbAlc was significantly lower in Actual-Renin ${ }_{\text {low. }}$. Also, fasting blood glucose concentration tended to be lower in Actual-Renin ${ }_{\text {low }}$ without reaching statistical significance (see Table 1).

As assessed by MR imaging, ejection fraction was significantly higher and left ventricular mass was significantly lower in Actual-Renin $n_{\text {high }}$ compared with Actual-Renin $n_{\text {low }}$. Global longitudinal strain and diastolic function were assessed by TTE and did not differ between the groups (see Table 1).

Analysis of variance in all patients with primary AI with ejection fraction or left ventricular mass as dependent variables and actual renin concentration as an independent variable showed significant between-group differences (ejection fraction: $F=24.526 ; p<0.001$; left ventricular mass: $F=6.254 ; p=0.025$ ).

In order to evaluate routine clinical signs and laboratory parameters of $\mathrm{MC}$ replacement therapy, patients grouped in Actual-Renin $n_{\text {low }}$ versus Actual-Renin ${ }_{\text {high }}$ were compared.

Salt craving and postural hypotension were three times

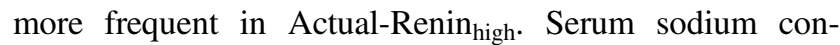

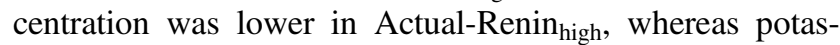
sium level was comparable (see Table 2).

\section{The impact of median long-term plasma renin concentration}

Patients suffering from primary AI were additionally grouped according to their plasma renin concentration during previous visits (Median-Renin ${ }_{\text {low }}$ vs. MedianRenin $\left._{\text {high }}\right)$. Age, sex, BMI, and disease duration were comparable between the groups. Also, the average daily dose of GC and MC replacement therapy was comparable. In addition, systolic and diastolic blood pressure at the time 
Table 1 Anthropometric characteristics, blood pressure, and parameters of glucose and lipid metabolism in Actual-Renin $n_{\text {low }}$ and Actual-Renin $n_{\text {high }}$ according to actual renin concentrations at the time of the study visit; magnetic resonance (MR) measurements were performed in $n=9$ patients in Actual-Renin $n_{\text {low }}$ and $n=7$ patients in Actual-Renin ${ }_{\text {high }}$; data are given as means \pm standard deviation or as median (minimum; maximum)

\begin{tabular}{|c|c|c|c|}
\hline & $\begin{array}{l}\text { Actual- } \\
\text { Renin }_{\text {low }}\end{array}$ & $\begin{array}{l}\text { Actual- } \\
\text { Renin }_{\text {high }}\end{array}$ & $p$ Value \\
\hline $\operatorname{Sex}(f / m)$ & $8 / 5$ & $13 / 5$ & n.s. \\
\hline Age (years) & $53 \pm 14$ & $57 \pm 14$ & n.s. \\
\hline BMI $\left(\mathrm{kg} / \mathrm{m}^{2}\right)$ & $25 \pm 5$ & $25 \pm 5$ & n.s. \\
\hline Disease duration (years) & $20 \pm 11$ & $18 \pm 9$ & n.s. \\
\hline $\mathrm{MC}$ dose $(\mathrm{mg} / \mathrm{d})$ & $0.06 \pm 0.04$ & $0.06 \pm 0.03$ & n.s. \\
\hline GC dose $(\mathrm{mg} / \mathrm{d})$ & $23 \pm 6$ & $23 \pm 5$ & n.s. \\
\hline $\begin{array}{l}\text { Plasma renin } \\
\text { concentration }(\mu \mathrm{IU} / \mathrm{ml})\end{array}$ & $27(2.2 ; 44)$ & $169(61 ; 2834)$ & $<0.001 *$ \\
\hline $\begin{array}{l}\text { Actual systolic } \\
\text { RR (mmHg) }\end{array}$ & $121 \pm 14$ & $133 \pm 19$ & n.s. \\
\hline $\begin{array}{l}\text { Actual diastolic } \\
\mathrm{RR}(\mathrm{mmHg})\end{array}$ & $72 \pm 6$ & $72 \pm 11$ & n.s. \\
\hline Triglycerides (mg/dl) & $113 \pm 75$ & $134 \pm 58$ & n.s. \\
\hline Total cholesterol (mg/dl) & $168 \pm 61$ & $187 \pm 54$ & n.s. \\
\hline HDL cholesterol (mg/dl) & $67 \pm 17$ & $61 \pm 14$ & n.s. \\
\hline LDL cholesterol (mg/dl) & $98 \pm 31$ & $111 \pm 32$ & n.s. \\
\hline Glucose (mg/dl) & $82 \pm 9$ & $89 \pm 10$ & 0.053 \\
\hline HbA1c (\%) & $5.1 \pm 0.2$ & $5.4 \pm 0.3$ & $0.027 *$ \\
\hline HOMA_IR & $2.0 \pm 1.8$ & $2.9 \pm 1.8$ & n.s. \\
\hline \multicolumn{4}{|c|}{ MR imaging and spectroscopy } \\
\hline Ejection fraction $(\%)$ & $55 \pm 3$ & $67 \pm 5$ & $0.001 *$ \\
\hline $\begin{array}{l}\text { Left ventricular mass } \\
\left(\mathrm{g} / \mathrm{m}^{2}\right)\end{array}$ & $73 \pm 10$ & $60 \pm 9$ & $0.025^{*}$ \\
\hline MYCL (\%) & $0.32 \pm 0.2$ & $0.43 \pm 0.4$ & n.s. \\
\hline HCL $(\%)$ & $2.1 \pm 1.7$ & $2.7 \pm 2.7$ & n.s. \\
\hline $\begin{array}{l}\text { Epicardial fat content } \\
\left(\mathrm{cm}^{2}\right)\end{array}$ & $14 \pm 7$ & $17 \pm 8$ & n.s. \\
\hline VAT/SAT ratio $\left(\mathrm{mm}^{2}\right)$ & $2.7 \pm 1.3$ & $2.2 \pm 0.8$ & n.s. \\
\hline \multicolumn{4}{|l|}{$T T E$} \\
\hline $\begin{array}{l}\text { Global longitudinal } \\
\text { strain }(\%)\end{array}$ & $-19 \pm 2$ & $-18 \pm 2$ & n.s. \\
\hline E/A ratio & $1.4 \pm 0.4$ & $-0.3 \pm 0.2$ & n.s. \\
\hline
\end{tabular}

$B M I$ body mass index, $M C$ dose daily dose of mineralocorticoid replacement therapy, $G C$ dose daily dose of glucocorticoid replacement therapy, actual systolic and diastolic RR systolic and diastolic blood pressure at the time point of the study visit, TTE transthoracic echocardiography, MYCL intramyocardial lipid content, $H C L$ hepatocellular lipid content, VAT/SAT visceral adipose tissue/subcutaneous adipose tissue

$* p<0.05$

of the study visit, as well as mean blood pressure of previous visits was similar in patients with high- and lowmedian renin concentrations.
Table 2 Clinical signs and laboratory parameters to evaluate mineralocorticoid replacement therapy in patients with actual renin concentrations at the time of the study visit $<50 \mu \mathrm{IU} / \mathrm{ml}$ (Actual$\operatorname{Renin}_{\text {low }}$ ) and $>50 \mu \mathrm{IU} / \mathrm{ml}$ (Actual-Renin ${ }_{\text {high }}$ ); data are given as means \pm standard deviation or as median (minimum; maximum)

\begin{tabular}{llll}
\hline & $\begin{array}{l}\text { Actual- } \\
\text { Renin }_{\text {low }}\end{array}$ & $\begin{array}{l}\text { Actual- } \\
\text { Renin }_{\text {high }}\end{array}$ & $p$ Value \\
\hline $\begin{array}{l}\text { Salt craving }(\% \text { of } \\
\text { patients) }\end{array}$ & 15 & 39 & n.s. \\
$\begin{array}{l}\text { Postural hypotension }(\% \\
\text { of patients) }\end{array}$ & 33 & 83 & $0.019^{*}$ \\
$\begin{array}{l}\text { Sodium }(\mathrm{mmol} / \mathrm{l}) \\
\text { Potassium }(\mathrm{mmol} / \mathrm{l})\end{array}$ & $139 \pm 3$ & $137 \pm 3$ & $0.042^{*}$ \\
$\begin{array}{l}\text { ACTH }(\mathrm{pg} / \mathrm{ml}) \\
\text { ADH }(\mathrm{pmol} / \mathrm{l})\end{array}$ & $232(2 ; 950)$ & $353(1 ; 1824)$ & n.s. \\
proBNP $(\mathrm{pg} / \mathrm{ml})$ & $6.4 \pm 3$ & $8.5 \pm 7$ & n.s. \\
\hline
\end{tabular}

$* p<0.05$

Similar to the comparison of actual renin concentrations, end-diastolic left ventricular mass was significantly higher and ejection fraction tended to be lower in Median-Renin ${ }_{\text {low }}$ compared with Median-Renin ${ }_{\text {high }}$, as assessed by MR imaging.

In TTE measurements, left ventricular global longitudinal strain, as well as diastolic function was not different between the two groups (see Table 3).

In correlation analysis, actual plasma renin concentration at the time of the study visit strongly correlated with left ventricular ejection fraction $(r=0.741 ; p<0.001)$. With regard to median renin concentration, a positive association with left ventricular ejection fraction $(r=0.435 ; p=0.081)$ and a negative association with end-diastolic septal thickness $(r=-0.429 ; p=0.086)$ could be found, yet both not reaching statistical significance.

\section{The impact of daily hydrocortisone dose}

No difference in glucose (glucose: $87 \pm 11$ vs. $85 \pm 10 \mathrm{mg}$ / dl; $p=$ n.s.; HbAlc: $5.4 \pm 0.3$ vs. $5.2 \pm 0.3 ; p=$ n.s.; HOMA_IR: $2.8 \pm 1.4$ vs. $2.4 \pm 1.8 ; \mathrm{p}=$ n.s.) and lipid (triglycerides: $137 \pm 70$ vs. $123 \pm 65 \mathrm{mg} / \mathrm{dl} ; p=$ n.s.; total cholesterol: $184 \pm 75$ vs. $180 \pm 50 \mathrm{mg} / \mathrm{dl}$; $p=$ n.s.) metabolism was found in patients with $>20 \mathrm{mg}(n=9)$ compared with patients with $\leq 20 \mathrm{mg}(n=23)$ of daily hydrocortisone.

In addition, parameters of cardiac function (ejection fraction: $59 \pm 8$ vs. $61 \pm 7 \% ; p=$ n.s.) and morphology (end-diastolic left ventricular mass: $66 \pm 6$ vs. $71 \pm 13 \mathrm{~g} / \mathrm{m}^{2}$; $p=$ n.s.) were comparable. Also, ectopic lipid content (HCL: $3.1 \pm 2.9$ vs. $2.0 \pm 1.5 \%$; $p=$ n.s.; MYCL: $0.31 \pm 0.2$ vs. $0.41 \pm 0.4 \% ; p=$ n.s. $)$, pericardial fat mass $(16 \pm 9$ vs. $15 \pm 6 \mathrm{~cm}^{2} ; p=$ n.s.), and the ratio of subcutaneous to visceral adipose tissue $\left(2.5 \pm 1.3\right.$ vs. $2.4 \pm 1.1 \mathrm{~mm}^{2} ; p=$ n.s. $)$ was not different. 
Table 3 Anthropometric characteristics, blood pressure, and parameters of glucose and lipid metabolism in patients divided into Median-Renin $_{\text {low }}$ and Median-Renin high $_{\text {according to plasma renin }}$ concentrations during the previous visits; mean time between the first and last of these previous visits was $31 \pm 16$ months; data are given as means \pm standard deviation or as median (minimum; maximum); magnetic resonance (MR) measurements were performed in $n=8$ patients in Actual-Renin $n_{\text {low }}$ and $n=9$ patients in Actual-Renin ${ }_{\text {high }}$

\begin{tabular}{|c|c|c|c|}
\hline & $\begin{array}{l}\text { Median- } \\
\text { Renin }_{\text {low }}\end{array}$ & Median-Renin $_{\text {high }}$ & $p$ Value \\
\hline $\operatorname{Sex}(\mathrm{f} / \mathrm{m})$ & $8 / 5$ & $13 / 6$ & n.s. \\
\hline Age (years) & $55 \pm 15$ & $54 \pm 14$ & n.s. \\
\hline BMI $\left(\mathrm{kg} / \mathrm{m}^{2}\right)$ & $25 \pm 5$ & $25 \pm 5$ & n.s. \\
\hline Disease duration (years) & $23 \pm 10$ & $16 \pm 9$ & n.s. \\
\hline MC dose $(\mathrm{mg} / \mathrm{d})$ & $0.05 \pm 0.03$ & $0.06 \pm 0.03$ & n.s. \\
\hline GC dose (mg/d) & $22 \pm 6$ & $23 \pm 5$ & n.s. \\
\hline Actual systolic RR (mmHg) & $123 \pm 12$ & $124 \pm 18$ & n.s. \\
\hline Actual diastolic RR (mmHg) & $72 \pm 7$ & $73 \pm 12$ & n.s. \\
\hline $\begin{array}{l}\text { Mean previous systolic } \\
\text { RR (mmHg) }\end{array}$ & $131 \pm 16$ & $122 \pm 16$ & n.s. \\
\hline $\begin{array}{l}\text { Mean previous diastolic } \\
\mathrm{RR}(\mathrm{mmHg})\end{array}$ & $81 \pm 7$ & $80 \pm 8$ & n.s. \\
\hline $\begin{array}{l}\text { Median renin concentration } \\
(\mu \mathrm{IU} / \mathrm{ml})\end{array}$ & $46(4 ; 96)$ & $180(101 ; 1501)$ & $<0.001 *$ \\
\hline $\begin{array}{l}\text { Actual renin concentration } \\
(\mu \mathrm{IU} / \mathrm{ml})\end{array}$ & $31(2 ; 194)$ & $149(25 ; 2834)$ & $<0.001 *$ \\
\hline Triglycerides (mg/dl) & $117 \pm 77$ & $134 \pm 54$ & n.s. \\
\hline Total cholesterol (mg/dl) & $171 \pm 64$ & $187 \pm 52$ & n.s. \\
\hline HDL cholesterol (mg/dl) & $62 \pm 17$ & $62 \pm 15$ & n.s. \\
\hline LDL cholesterol (mg/dl) & $106 \pm 40$ & $109 \pm 27$ & n.s. \\
\hline Glucose (mg/dl) & $86 \pm 10$ & $85 \pm 10$ & n.s. \\
\hline HbAlc (\%) & $5.1 \pm 0.3$ & $5.3 \pm 0.3$ & n.s. \\
\hline HOMA_IR & $2.6 \pm 2.3$ & $2.5 \pm 1.2$ & n.s. \\
\hline \multicolumn{4}{|l|}{ MR imaging and spectroscopy } \\
\hline Ejection fraction $(\%)$ & $56 \pm 4$ & $63 \pm 8$ & 0.073 \\
\hline Left ventricular mass $\left(\mathrm{g} / \mathrm{m}^{2}\right)$ & $76 \pm 11$ & $64 \pm 9$ & $0.029 *$ \\
\hline MYCL (\%) & $0.29 \pm 0.2$ & $0.43 \pm 0.4$ & n.s. \\
\hline HCL (\%) & $1.8 \pm 1.7$ & $2.9 \pm 2.3$ & n.s. \\
\hline Epicardial fat content $\left(\mathrm{cm}^{2}\right)$ & $16 \pm 7$ & $15 \pm 8$ & n.s. \\
\hline VAT/SAT ratio $\left(\mathrm{mm}^{2}\right)$ & $2.6 \pm 1.4$ & $2.3 \pm 0.9$ & n.s. \\
\hline \multicolumn{4}{|l|}{ TTE } \\
\hline Global longitudinal strain (\%) & $-19 \pm 2$ & $-19 \pm 2$ & n.s. \\
\hline E/A ratio & $1.3 \pm 0.8$ & $1.1 \pm 0.4$ & n.s. \\
\hline
\end{tabular}

BMI body mass index, $M C$ dose daily dose of mineralocorticoid replacement therapy, $G C$ dose daily dose of glucocorticoid replacement therapy, actual systolic and diastolic $R R$ systolic and diastolic blood pressure at the time point of the study visit, mean previous systolic and diastolic $R R$ average systolic and diastolic blood pressure during the previous four routine clinical visits at the endocrinology outpatients clinic, TTE transthoracic echocardiography, MYCL intramyocardial lipid content, $H C L$ hepatocellular lipid content, VAT/SAT visceral adipose tissue/subcutaneous adipose tissue

$* p<0.05$

\section{Comparison of patients suffering from adrenal insufficiency and healthy controls}

Systolic and diastolic blood pressure and lipid metabolism were similar between the groups. With regard to glucose metabolism, fasting glucose concentration was lower in AI, whereas HbA1c and HOMA_IR were comparable with controls. In addition, ectopic lipid content in the liver and heart, as well as epicardial fat mass was similar in patients with $\mathrm{AI}$ and controls.

Ejection fraction was significantly lower in patients suffering from AI, whereas no differences in parameters of cardiac morphology were found. When healthy subjects were compared with patients grouped according to their plasma renin concentration of previous visits, only differences between Median-Renin $n_{\text {low }}$ and controls could be observed (see Fig. 2). For a detailed list of all parameters see Table 4.

\section{Discussion}

Our data demonstrate a significant impact of RAS activity on heart function and morphology in patients suffering from primary AI. Higher renin concentrations are associated with a favorable cardiac function and morphology, i.e., an improved systolic function and a lower left ventricular mass. Interestingly, these changes were independent of conventional cardiovascular risk factors like body weight, blood pressure, glucose, and lipid metabolism, supporting the importance of direct MC action on the heart.

Renin concentrations are inversely associated with MC activity in patients with primary AI, as well as in the general population. Autonomous hypersecretion of aldosterone results in a higher cardiovascular morbidity and mortality compared with age- and sex-matched patients, with essential hypertension and the same degree of blood pressure elevation [14]. This increased risk persists even during medical treatment with MC antagonists by aldosterone receptor blockers, as long as plasma renin concentration remains suppressed [9]. Moreover, treatment with aldosterone antagonists in chronic heart failure is well established and known to reduce hospitalization and mortality, wherefore aldosterone antagonists are included in the therapeutic algorithm of recent clinical practice guidelines for heart failure therapy [19]. Aldosterone modulates different cardiovascular risk factors in many ways. Within the heart, aldosterone promotes cardiac fibrosis by stimulation of collagen and fibroblast proliferation, therefore contributing to left ventricular hypertrophy [20, 21]. Moreover, aldosterone not only affects arterial stiffness, vascular compliance, and relaxation, but also increases intravascular volume by sodium retention in the kidney, which all together contribute to an increased afterload and thereby to cardiac hypertrophy [22]. These mechanisms of aldosterone action are likely to explain the observed differences of left ventricular mass and function in our patients.

Of note, elevated renin is strongly correlated with increased concentration of AT2, which is well known for its 

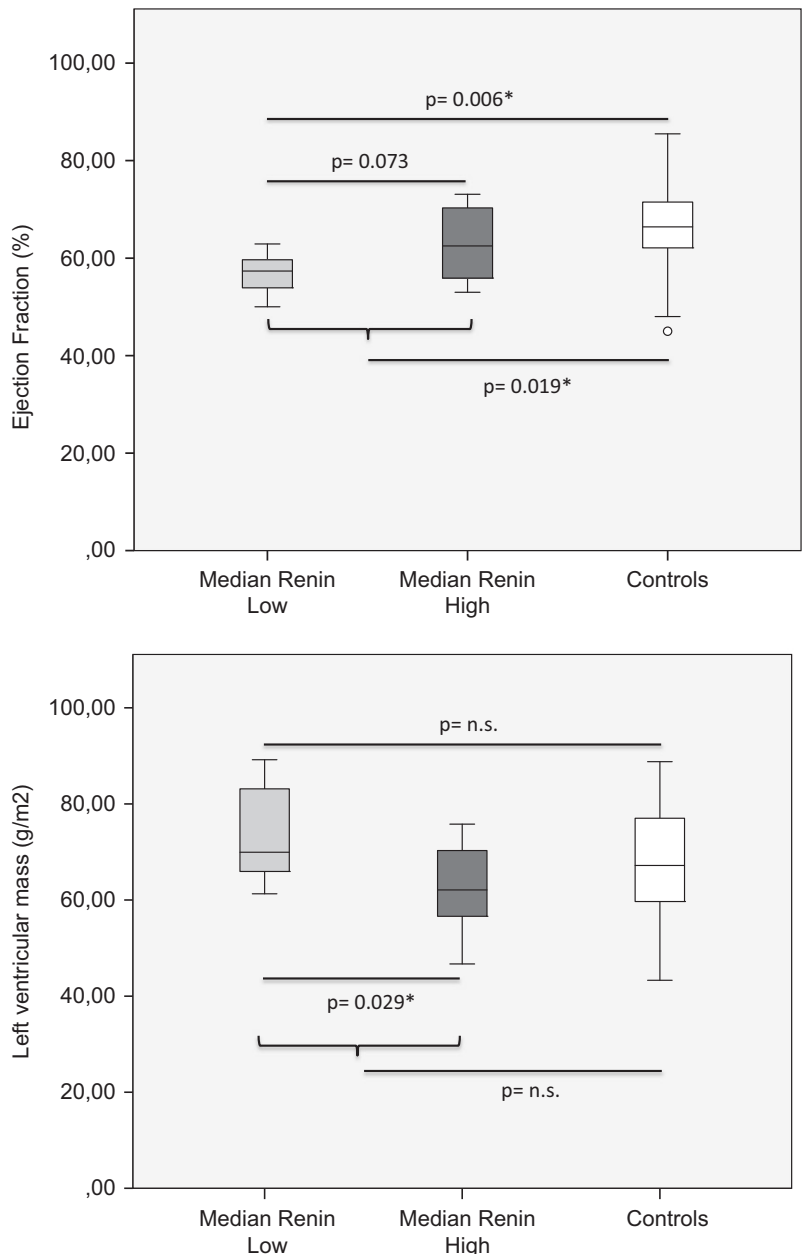

Fig. 2 Ejection fraction and left ventricular mass in patients with normal to slightly elevated (Median Renin Low; bright gray boxplot), elevated (Median Renin High; dark gray boxplot) plasma renin concentrations during the previous four routine clinical visits at the endocrinology outpatients clinic, and healthy controls (Controls; white boxplot); comparison between different groups was performed by using unpaired Student's $t$ test; * $p<0.05$

adverse effects on vasculature and the myocardium, similar to aldosterone [11]. Therefore, it was speculated that an inappropriate reduction of fludrocortisone dose in patients with primary AI should be avoided to protect from the deleterious actions of AT2 [23]. This assumption cannot be confirmed by the results observed in our patients. The most likely explanation might be that in primary AI, increased RAS activity not only results in higher levels of AT2, but also increases concentrations of other potentially cardioprotective angiotensin metabolites like Ang1-7, what we observed in previous preliminary studies [13]. Ang1-7 is decreased in acute heart failure and might counteract AT2 by induction of vasodilation, therefore preventing the development of left ventricular hypertrophy $[12,24]$. Thus, we suppose that the observed rise in RAS activity in
Table 4 Results of $n=17$ patients suffering from adrenal insufficiency (AI), who underwent magnetic resonance spectroscopy and imaging measurements and $n=34$ healthy controls; anthropometric characteristics, data of laboratory tests, and results of magnetic resonance spectroscopy (MYCL intramyocardial lipid content, HCL hepatocellular lipid content) and imaging (parameters of cardiac function and morphology and epicardial fat) measurements are given as means \pm standard deviation or as median (minimum; maximum); BMI body mass index

\begin{tabular}{|c|c|c|c|}
\hline & AI & Controls & $p$ Value \\
\hline Age (years) & $48 \pm 12$ & $46 \pm 18$ & n.s. \\
\hline BMI $\left(\mathrm{kg} / \mathrm{m}^{2}\right)$ & $23 \pm 3$ & $24 \pm 3$ & n.s. \\
\hline Systolic RR (mmHg) & $120 \pm 12$ & $129 \pm 25$ & n.s. \\
\hline Diastolic RR (mmHg) & $72 \pm 6$ & $75 \pm 12$ & n.s. \\
\hline Triglycerides (mg/dl) & $111 \pm 62$ & $117 \pm 95$ & n.s. \\
\hline Total cholesterol (mg/dl) & $180 \pm 54$ & $192 \pm 35$ & n.s. \\
\hline HDL cholesterol (mg/dl) & $61 \pm 14$ & $56 \pm 13$ & n.s. \\
\hline LDL cholesterol (mg/dl) & $112 \pm 28$ & $112 \pm 33$ & n.s. \\
\hline Glucose (mg/dl) & $82 \pm 8$ & $89 \pm 8$ & $0.010^{*}$ \\
\hline $\mathrm{HbAlc}(\%)$ & $5.3 \pm 0.3$ & $5.2 \pm 0.4$ & n.s. \\
\hline HOMA_IR & $1.9 \pm 1$ & $2.4 \pm 1.4$ & n.s. \\
\hline Ejection fraction (\%) & $56 \pm 4$ & $63 \pm 8$ & $0.019^{*}$ \\
\hline End-diastolic volume $\left(\mathrm{ml} / \mathrm{m}^{2}\right)$ & $55 \pm 9$ & $52 \pm 17$ & n.s. \\
\hline End-systolic volume $\left(\mathrm{ml} / \mathrm{m}^{2}\right)$ & $22 \pm 6$ & $18 \pm 8$ & n.s. \\
\hline Stroke volume $\left(\mathrm{ml} / \mathrm{m}^{2}\right)$ & $33 \pm 6$ & $33 \pm 11$ & n.s. \\
\hline Cardiac index $\left(1 / \mathrm{min} / \mathrm{m}^{2}\right)$ & $2.1 \pm 0.3$ & $2.3 \pm 0.6$ & n.s. \\
\hline $\begin{array}{l}\text { End-diastolic myocardial } \\
\text { mass }\left(\mathrm{g} / \mathrm{m}^{2}\right)\end{array}$ & $67 \pm 11$ & $67 \pm 13$ & n.s. \\
\hline $\begin{array}{l}\text { End-diastolic septal } \\
\text { thickness (mm) }\end{array}$ & $8.8 \pm 1.3$ & $9 \pm 1.6$ & n.s. \\
\hline Epicardial fat $\left(\mathrm{cm}^{2}\right)$ & $16 \pm 7$ & $15 \pm 10$ & n.s. \\
\hline MYCL $(\%)$ & $0.4 \pm 0.3$ & $0.4 \pm 0.3$ & n.s. \\
\hline HCL $(\%)$ & $1.5(0.3 ; 8.1)$ & $3.2(0.4 ; 23)$ & n.s. \\
\hline
\end{tabular}

$B M I$ body mass index

$* p<0.05$

primary AI, which closely correlates with plasma renin concentration [13], results in a well-balanced increase of various angiotensin metabolites with protective, as well as harmful effects on cardiovascular risk factors.

Only limited data exist on heart function and the prevalence of heart failure in patients suffering from primary AI. Animal models nicely demonstrate the necessity of GC and $\mathrm{MC}$ replacement to maintain proper cardiac function in adrenalectomized rats [25]. In humans, older, crosssectional studies in 22 patients with AI and long-term disease duration, heart failure was found in almost one-third of the patients [26]. This is in contrast to our study, in which systolic heart function was normal in all patients, despite a long disease duration of $19 \pm 10$ years. Systolic heart function was better in matched healthy controls compared with patients with primary AI. This difference was especially marked, when patients were divided according to their previous median renin concentrations, showing significantly worse ejection fraction in the group of MedianRenin $_{\text {low. }}$ Therefore, optimizing MC replacement therapy might help to prevent the development of heart failure in elderly patients with primary AI. 
Clinical practice guidelines and expert comments recommend an upper normal or slightly elevated plasma renin concentration to aim for adequate $\mathrm{MC}$ replacement therapy [4, 14, 23, 27], which cannot be supported by our data. Due to the non-interventional, cross-sectional design of our study, we are not able to answer the question, if a reduction in daily fludrocortisone dose might be beneficial for heart function and morphology. However, our data clearly demonstrate that higher renin concentrations are associated with a favorable cardiac performance, i.e., better left ventricular systolic function and left ventricular smaller mass.

Of note, MC replacement plays an important role to maintain quality of life in patients with primary AI [28] and improves mood and cognition [29]. Evaluation of adequate MC therapy depends on clinical signs like blood pressure or salt craving, and biochemical markers, including sodium, potassium, and plasma renin concentration [23]. In our study, salt craving was two times more common, and also a postural drop in systolic blood pressure during the Schellong test was only observed in Actual-Renin high. $_{\text {. }}$

A limitation of our study is the intra-individual variability of plasma renin concentration, mainly depending on daily salt and water intake, which was not standardized during the study days. To address this issue, Median-Renin concentrations of previous visits at the endocrine outpatients' clinic were included for analysis to investigate the effects of RAS activity during a longer observation period. Of note, despite distinct changes in renin concentrations, $87.5 \%$ of all included patients stayed within their groups, i.e., Actual-Renin low $_{\text {low }}=$ Median-Renin $_{\text {low }} /$ Actual-Renin ${ }_{\text {high }}$ $=$ Median-Renin $_{\text {high }}$.

With regard to GC replacement, large-cohort studies demonstrate an impact of the daily dose of hydrocortisone on conventional cardiovascular risk factors like hypertension, BMI, and waist circumference [5], whereas other studies were not able to confirm this association [30, 31]. When patients were divided into two groups according to their GC replacement therapy, glucose and lipid metabolism were not different in patients with $>20 \mathrm{mg}$ of hydrocortisone per day. This might be due to the small sample size of patients in each group, since routine laboratory parameters show high variation. However, also ectopic lipid content in the liver, as well as the ratio of subcutaneous to visceral adipose tissue, which are both sensitive markers for insulin sensitivity and energy homeostasis in smaller cohorts [32], were comparable.

Taken together, our results demonstrate that higher renin concentrations are associated with a favorable cardiac function and morphology in patients with primary AI. If a reduction in $\mathrm{MC}$ replacement therapy prevents the development of heart failure and reduces cardiovascular mortality should be evaluated in future prospective trials.
Acknowledgements The authors thank all participants for taking part at study-related experiments. Open access funding provided by Medical University of Vienna.

Funding This study was in parts funded by grants from the Austrian Association of Endocrinology and Metabolism (ÖGES) to P.W.

\section{Compliance with ethical standards}

Conflict of interest The authors declare that they have no conflict of interest.

Ethics approval All procedures performed were in accordance with the ethical standards of the institutional and/or national research committee and with the 1964 Helsinki declaration and its later amendments or comparable ethical standards (Ethical commission of the Medical University of Vienna; No. 2121/2017).

Publisher's note: Springer Nature remains neutral with regard to jurisdictional claims in published maps and institutional affiliations.

Open Access This article is distributed under the terms of the Creative Commons Attribution 4.0 International License (http://crea tivecommons.org/licenses/by/4.0/), which permits unrestricted use, distribution, and reproduction in any medium, provided you give appropriate credit to the original author(s) and the source, provide a link to the Creative Commons license, and indicate if changes were made.

\section{References}

1. A.B. Grossman, G. Johansson, M. Quinkler, P. Zelissen, Perspectives on the management of adrenal insufficiency: clinical insights from across Europe. Eur. J. Endocrinol. 169, R165-R175 (2013)

2. M.M. Erichsen, K. Lovas, K.J. Fougner, J. Svartberg, E.R. Hauge, J. Bollerslev, J.P. Berg, B. Mella, E.S. Husebye, Normal overall mortality rate in Addison's disease, but young patients are at risk of premature death. Eur. J. Endocrinol. 160, 233-237 (2009)

3. R. Bergthorsdottir, M. Leonsson-Zachrisson, A. Oden, G. Johannsson, Premature mortality in patients with Addison's disease: a population-based study. J. Clin. Endocrinol. Metab. 91, 4849-4853 (2006)

4. M. Quinkler, W. Oelkers, H. Remde, B. Allolio, Mineralocorticoid substitution and monitoring in primary adrenal insufficiency. Best. Pract. Res. Clin. Endocrinol. Metab. 29, 17-24 (2015)

5. H. Filipsson, J.P. Monson, M. Koltowska-Haggstrom, A. Mattsson, G. Johannsson, The impact of glucocorticoid replacement regimens on metabolic outcome and comorbidity in hypopituitary patients. J. Clin. Endocrinol. Metab. 91, 3954-3961 (2006)

6. A.M. Isidori, M.A. Venneri, C. Graziadio, C. Simeoli, D. Fiore, V. Hasenmajer, E. Sbardella, D. Gianfrilli, C. Pozza, P. Pasqualetti, S. Morrone, A. Santoni, F. Naro, A. Colao, R. Pivonello, A. Lenzi, Effect of once-daily, modified-release hydrocortisone versus standard glucocorticoid therapy on metabolism and innate immunity in patients with adrenal insufficiency (DREAM): a single-blind, randomised controlled trial. Lancet Diab. Endocrinol. 6, 173-185 (2018)

7. G. Johannsson, A.G. Nilsson, R. Bergthorsdottir, P. Burman, P. Dahlqvist, B. Ekman, B.E. Engstrom, T. Olsson, O. Ragnarsson, M. Ryberg, J. Wahlberg, B.M. Biller, J.P. Monson, P.M. Stewart, 
H. Lennernas, S. Skrtic, Improved cortisol exposure-time profile and outcome in patients with adrenal insufficiency: a prospective randomized trial of a novel hydrocortisone dual-release formulation. J. Clin. Endocrinol. Metab. 97, 473-481 (2012)

8. J.W. Funder, R.M. Carey, F. Mantero, M.H. Murad, M. Reincke, H. Shibata, M. Stowasser, W.F. Young Jr., The management of primary aldosteronism: case detection, diagnosis, and treatment: an endocrine society clinical practice guideline. J. Clin. Endocrinol. Metab. 101, 1889-1916 (2016)

9. G. Hundemer, G. Curhan, N. Yozamp, M. Wang, A. Vaidya, Cardiometabolic outcomes and mortality in medically treated primary aldosteronism: a retrospective cohort study. Lancet Diab. Endocrinol. 6, 51-59 (2018)

10. M. Ruiz-Ortega, O. Lorenzo, M. Ruperez, V. Esteban, Y. Suzuki, S. Mezzano, J. Plaza, J. Egido, Role of the renin-angiotensin system in vascular diseases - expanding the field. Hypertension 38, 1382-1387 (2001)

11. M.B. Taubman, Angiotensin II: a vasoactive hormone with everincreasing biological roles. Circ. Res. 92, 9-11 (2003)

12. R. Basu, M. Poglitsch, H. Yogasundaram, J. Thomas, B.H. Rowe, G. Y. Oudit, Roles of Angiotensin Peptides and Recombinant Human ACE2 in Heart Failure. J. Am. Coll. Cardiol. 69, 805-819 (2017)

13. P. Wolf, J. Mayr, M. Poglitsch, A. Gessl, A. Luger, Y. Winhofer, M. Krebs, The renin-angiotensin-aldosteron system in primary adrenal insufficiency. Endocr. Abstr. 56, 47 (2018)

14. S.R. Bornstein, B. Allolio, W. Arlt, A. Barthel, A. Don-Wauchope, G.D. Hammer, E.S. Husebye, D.P. Merke, M.H. Murad, C. A. Stratakis, D.J. Torpy, Diagnosis and treatment of primary adrenal insufficiency: an Endocrine Society Clinical Practice Guideline. J. Clin. Endocrinol. Metab. 101, 364-389 (2016)

15. L.G. Rudski, W.W. Lai, J. Afilalo, L. Hua, M.D. Handschumacher, K. Chandrasekaran, S.D. Solomon, E.K. Louie, N.B. Schiller, Guidelines for the echocardiographic assessment of the right heart in adults: a report from the American Society of Echocardiography endorsed by the European Association of Echocardiography, a registered branch of the European Society of Cardiology, and the Canadian Society of Echocardiography. J. Am. Soc. Echocardiogr. 23, 685-713 (2010). quiz 786-688

16. P. Wolf, M. Krssak, Y. Winhofer, C.H. Anderwald, E. Zwettler, I. Just Kukurova, A. Gessl, S. Trattnig, A. Luger, S. BaumgartnerParzer, M. Krebs, Cardiometabolic phenotyping of patients with familial hypocalcuric hypercalcemia. J. Clin. Endocrinol. Metab. 99, E1721-E1726 (2014)

17. P. Wolf, Y. Winhofer, M. Krssak, S. Smajis, J. Harreiter, L. KosiTrebotic, C. Furnsinn, C.H. Anderwald, S. Baumgartner-Parzer, S. Trattnig, A. Luger, M. Krebs, Suppression of plasma free fatty acids reduces myocardial lipid content and systolic function in type 2 diabetes. Nutr. Metab. Cardiovasc Dis. 26, 387-392 (2016)

18. P. Wolf, Y. Winhofer, S. Smajis, D. Jankovic, C.H. Anderwald, S. Trattnig, A. Luger, M. Krebs, M. Krssak, Pericardial—rather than intramyocardial fat is independently associated with left ventricular systolic heart function in metabolically healthy humans. PloS ONE 11, e0151301 (2016)
19. C.W. Yancy, M. Jessup, B. Bozkurt, J. Butler, D.E. Casey Jr., M. M. Colvin, M.H. Drazner, G.S. Filippatos, G.C. Fonarow, M.M. Givertz, S.M. Hollenberg, J. Lindenfeld, F.A. Masoudi, P.E. McBride, P.N. Peterson, L.W. Stevenson, C. Westlake, 2017 ACC/AHA/HFSA focused update of the 2013 ACCF/AHA Guideline for the Management of Heart Failure: a report of the American College of Cardiology/American Heart Association Task Force on Clinical Practice Guidelines and the Heart Failure Society of America. Circulation 136, e137-e161 (2017)

20. C. Catena, G. Colussi, G. Brosolo, M. Novello, L.A. Sechi, Aldosterone and left ventricular remodeling. Horm. Metab. Res 47, 981-986 (2015)

21. S.I. McFarlane, J.R. Sowers, Cardiovascular endocrinology 1: aldosterone function in diabetes mellitus: effects on cardiovascular and renal disease. J. Clin. Endocrinol. Metab. 88, 516-523 (2003)

22. B. Schmitz, S.M. Brand, E. Brand, Aldosterone signaling and soluble adenylyl cyclase-a nexus for the kidney and vascular endothelium. Biochim. Biophys. Acta 1842, 2601-2609 (2014)

23. D. Esposito, D. Pasquali, G. Johannsson, Primary adrenal insufficiency: managing mineralocorticoid replacement therapy. J. Clin. Endocrinol. Metab. 103, 376-387 (2018)

24. R.A. Santos, A.J. Ferreira, T. Verano-Braga, M. Bader, Angiotensin-converting enzyme 2, angiotensin-(1-7) and Mas: new players of the renin-angiotensin system. J. Endocrinol. 216, R1-R17 (2013)

25. D. Cruz-Topete, P.H. Myers, J.F. Foley, M.S. Willis, J.A. Cidlowski, Corticosteroids are essential for maintaining cardiovascular function in male mice. Endocrinology 157, 2759-2771 (2016)

26. Knowlton A., and Baer L. Cardiac failure in Addison's disease. Am. J. Med. 74, 829-836 (1983)

27. W.J. Inder, C. Meyer, P.J. Hunt, Management of hypertension and heart failure in patients with Addison's disease. Clin. Endocrinol. 82, 789-792 (2015)

28. S. Hahner, M. Loeffler, M. Fassnacht, D. Weismann, A.C. Koschker, M. Quinkler, O. Decker, W. Arlt, B. Allolio, Impaired subjective health status in 256 patients with adrenal insufficiency on standard therapy based on cross-sectional analysis. J. Clin. Endocrinol. Metab. 92, 3912-3922 (2007)

29. K. Schultebraucks, K. Wingenfeld, C. Otte, M. Quinkler, The role of fludrocortisone in cognition and mood in patients with primary adrenal insufficiency (Addison's Disease). Neuroendocrinology 103, 315-320 (2016)

30. B. Bleicken, S. Hahner, M. Loeffler, M. Ventz, O. Decker, B. Allolio, M. Quinkler, Influence of hydrocortisone dosage scheme on health-related quality of life in patients with adrenal insufficiency. Clin. Endocrinol. 72, 297-304 (2010)

31. R.L. Rushworth, D.J. Torpy, Modern hydrocortisone replacement regimens in adrenal insufficiency patients and the risk of adrenal crisis. Horm. Metab. Res 47, 637-642 (2015)

32. P. Wolf, Y. Winhofer, C.H. Anderwald, M. Krssak, M. Krebs, Intracellular lipid accumulation and shift during diabetes progression. Wien. Med Wochenschr. 164, 320-329 (2014) 